\title{
Teaching Technology-Based Entrepreneurship through a Universal Innovation Framework
}

\author{
Lotfi Belkhir \\ Associate Professor \\ Xerox Centre for Engineering, Entrepreneurship \& Innovation \\ School of Engineering Practice, Faculty of Engineering \\ McMaster University \\ Email: belkhir@mcmaster.ca
}

\begin{abstract}
This paper discusses the experiential teaching of innovation-based entrepreneurship through a Universal Innovation Framework. The framework clearly delineates the fundamental differences between invention as a technical event and innovation as a social event. It also offers a general and practical framework for the innovation student to test whether their new venture idea meets all the requirements of innovation. Finally, it offers a holistic and iterative approach to developing that innovation according to a stage-gate model that provides a structured methodology to successfully developing a new innovation-based enterprise.
\end{abstract}

Keywords: Strategic Innovation, Entrepreneurship Education, Lean Startup Model, Universal Innovation Framework

\section{INTRODUCTION}

The Kauffman Foundation of entrepreneurship reported recently in an extensive study entitled "Entrepreneurship Education Comes of Age on Campus: The challenges and rewards of bringing entrepreneurship to higher education " that in the last decade alone, entrepreneurship education has became "a staple of American higher education" [1]. The report mentions that the number of entrepreneurship courses offered by twoyear and four-year institutions in the United States exploded from about 250 in 1985 to more than 5,000 courses in 2008. These courses involve over 400,000 students per year and almost 9,000 faculty to teach them. Furthermore, universities are becoming increasingly aware of the importance of their role in building the nation's entrepreneurship capability and infrastructure as a key enabler of economic competitiveness and job creation.

Indeed, in yet another publication by the Kauffman Foundation, the report showed that $100 \%$ of all the net jobs created between 1977-2005 were created by startups, defined as a firm from zero to 1-year of age [2].

On the other hand and unlike the teaching of the traditional disciplines, there seems to be no monolithic model for how to teach entrepreneurship in a university setting. Some universities have opted to offer formal curriculums in the forms of certificate, minor, major or even a master's degree; others have opted for a noncurricular program instead through workshops and speaker series, while others have a combination of both.

A common challenge among the curricular programs is how to teach technology-based entrepreneurship in a way that lends itself to an experiential, structured, repeatable and effective process. In recent years, the "Lean Startup Model", by Stephen Blank and Eric Ries, has emerged as the model of choice to that end [3][4]. Nonetheless, many universities continue to teach entrepreneurship in the same way as they teach Accounting, Finance and Marketing, and where the main outcome of the course is the development of a Business Plan. As new research by Harvard Business School's Shikhar Ghosh shows, 75\% of all start-ups that start with a Business Plan fail [5][6].

The key difference between the traditional model of teaching entrepreneurship and the Lean Startup Model (LSM) is that the former is a linear model that starts with an untested hypothesis, while the latter is a recursive one that tests and validates (or refutes) the initial foundational assumptions. The LSM proposes to approach the startup process as a discovery process that focuses on the customer discovery and customer development process and continuously iterates between the customer needs and the product requirements until there is a full alignment between the two. This process is reminiscent to some of the numerical methods used in converging to the solutions of non-linear problems. This process is explained in detail in Steve Blank's book "The Four Steps to the Epiphany"[3]. The LSM however does not explicitly integrate or substitute for the Product Development 
Process (PDP), but rather assumes that the PDP is a companion and parallel process to the LSM.

In this paper, we present an integrated model for teaching technology-based entrepreneurship in a way that seamlessly integrates the LSM with PDP through a practical and Universal Innovation Framework (UIF).

\section{ANATOMY OF INNOVATION}

A most popular misconception, both conceptually and in practice, is that innovation is the successful commercialization of an invention, i.e. (innovation = invention + exploitation/commercialization) [7]. Companies around the world use routinely the number of patents (and/or publications in the case of research institutions) issued to them every year, and their R\&D spend as proxy metrics of their level of innovation. Yet, our research shows that there is zero correlation between a company's total issued patents or its R\&D Spend with its level of innovation. For instance Figure 1 and 2 below show the "Top 10 Inventive Companies in the World" in 2011/12 and the "Most Innovative Companies Ranking" in 2013 respectively. For instance, Apple which ranked No. 1 as the most innovative company in the World in the last 3 years since 2010 spends less on R\&D than any of the top Technology Spenders and received less patents than any of the top inventive companies.

Figure 1: Top 10 Inventive Companies in the World in 20122011

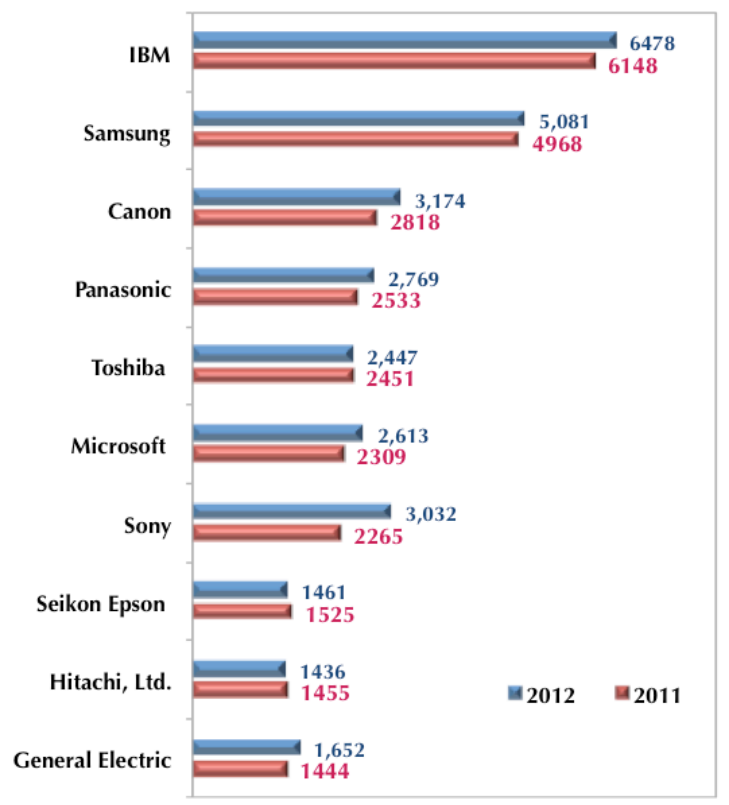

The fundamental mistake that continues to be made is a lack of a defining distinction between the very different natures of invention and innovation, and hence the unchallenged assumption that innovation is always invention-driven.

Invention is clearly defined by the development of a product idea or a process that meets three clear and objective criteria; namely: (i) novelty, (ii) usefulness and (iii) non-obviousness to the expert in the art [8]. These are the very criteria that are used by a patent examiner to decide on the patentability of a proposed invention. If the idea meets those requirements, then a patent is issued to the author of that idea, which makes him or her an "inventor", and his idea becomes an "invention". Because of these three criteria, an invention is essentially and primarily a technical event. Inventions require engineers and scientists to develop them, and hence a commensurate $\mathrm{R} \& \mathrm{D}$ investment is required as well.

Figure 2: Most Innovative Companies Ranking (courtesy of strategy\& - formerly known as Booz \& co.)

\begin{tabular}{|c|c|c|c|c|c|c|c|c|c|}
\hline 2005 & & 2006 & 2007 & 2008 & 2009 & 2010 & 2011 & 2012 & 2013 \\
\hline \multicolumn{10}{|c|}{ 2013: 10 Most Innovative Companies } \\
\hline $\begin{array}{l}2013 \\
\text { Rank }\end{array}$ & $\hat{\theta}$ & $\begin{array}{l}2012 \\
\text { Rank }\end{array}$ & \multicolumn{2}{|l|}{ Company } & \multicolumn{2}{|c|}{ Geography } & \multicolumn{2}{|l|}{ Industry } & $\begin{array}{l}\text { R\&D } \\
\text { Spend } \\
\text { (\$Bn)* }\end{array}$ \\
\hline 1 & - & 1 & \multicolumn{2}{|l|}{ Apple } & \multicolumn{2}{|c|}{ United States } & \multicolumn{2}{|c|}{ Computing \& Electronics } & 3.4 \\
\hline 2 & - & 2 & \multicolumn{2}{|l|}{ Google } & \multicolumn{2}{|c|}{ United States } & \multicolumn{2}{|c|}{ Software \& Internet } & 6.8 \\
\hline 3 & $\boldsymbol{\Delta}$ & 4 & \multicolumn{2}{|l|}{ Samsung } & \multicolumn{2}{|c|}{ South Korea } & \multicolumn{2}{|c|}{ Computing \& Electronics } & 10.4 \\
\hline 4 & - & 10 & \multicolumn{2}{|l|}{ Amazon } & \multicolumn{2}{|c|}{ United States } & \multicolumn{2}{|c|}{ Software \& Internet } & 4.6 \\
\hline 5 & $\mathbf{T}$ & 3 & \multicolumn{2}{|l|}{$3 \mathrm{M}$} & \multicolumn{2}{|c|}{ United States } & \multicolumn{2}{|l|}{ Industrials } & 1.6 \\
\hline 6 & $\checkmark$ & 5 & \multicolumn{2}{|c|}{ General Electric } & \multicolumn{2}{|c|}{ United States } & \multicolumn{2}{|l|}{ Industrials } & 4.5 \\
\hline 7 & $\checkmark$ & 6 & \multicolumn{2}{|c|}{ Microsoft } & \multicolumn{2}{|c|}{ United States } & \multicolumn{2}{|c|}{ Software \& Internet } & 9.8 \\
\hline 8 & $\wedge$ & 9 & \multicolumn{2}{|l|}{ IBM } & \multicolumn{2}{|c|}{ United States } & \multicolumn{2}{|c|}{ Software \& Internet } & 6.3 \\
\hline 9 & New & - & \multicolumn{2}{|l|}{ Tesla Motors } & \multicolumn{2}{|c|}{ United States } & \multicolumn{2}{|l|}{ Automotive } & 0.3 \\
\hline 10 & New & - & \multicolumn{2}{|l|}{ Facebook } & \multicolumn{2}{|c|}{ United States } & \multicolumn{2}{|c|}{ Software \& Internet } & 1.4 \\
\hline
\end{tabular}

On the other hand, the innovation level of a company, as we've seen above, is anything but correlated to patents or R\&D spending. Apple ranks as the top innovator in the world, no thanks to their level of R\&D spend or number of patents, but rather by paying close attention to the needs of the marketplace and by emancipating the pains, needs and wants of the user. The R\&D investment that is made is needs-driven and laser-focused on developing the products that will uniquely meet those needs of their market audience and dedicated to producing the highest quality experience for their customers. It is not some certain percentage of sales that is left to some VP's and their strategic staffers to allocate in order to keep their engineers employed.

From that perspective, Apple does not allocate its R\&D budget based on a percentage of sales like most companies do, but rather seems to allocate it based on their ability to identify hidden but large market opportunities on the one hand, and their ability to leverage their core competencies to develop the novel products that will fulfill that market opportunity, even if it's outside their core business, e.g. music (iTunes) and telecom (the iPhone). We've also more recently seen Google develop similar innovation capability with the rapid success and market penetration of the Android OS. Apple is a master at not only developing the most useful, intuitive and addictive products in the IT world, but they're also second to none at developing the business models that allow them to deliver those to the largest spectrum possible of users, while at the same time

CEEA14; Teaching Technology-Based Entrepreneurship Using a Universal Innovation Framework - Calgary, Alberta 
extracting the highest per unit margins from their product sales. From this vantage point, this approach to innovation makes the technical aspect of innovation, not only a relatively smaller part of the whole process, but also a subservient part that is motivated and driven by the societal needs of the market place and the added value that their products bring to a very large segment of the global society. This makes Innovation a primarily social event.

When viewed from the perspective of being a social, rather than a technical event, one can take a radically fresh approach to innovation in a way that makes it more easily definable within a universal, practical and manageable framework, as shown in the following section.

In this paper we define a practical and universal Innovation framework that defines innovation by its components and the dynamic and recursive interdependencies between those components, hence its practicality and usefulness in identifying, building and managing innovation in both an educational as well as research setting.

In Figure 3 we illustrate our Universal Innovation Framework (UIF) as being composed of:

Three major components:

1) The Market need

2) The product or service that uniquely meets this need; where product is taken in its most general sense.

3) The Business Model that effectively delivers this product to that audience need

And two attributes:

4) A Novelty aspect that is related to either the product/service, the business model or the audience needs, and

5) A Sustainable Competitive Advantage that ensures the longevity of the shared value creation to both the innovator and its market by effectively blocking the entry of potential competitors.

Each major component of this innovation model has several essential elements that need to be addressed interdependently of other essential elements of another component of the model. For example, the Value Proposition, which is an essential element of the Market Need, also depends on the product features as well as the competitive positioning of that product. Similarly, the Sales Channels element depends on the Market Segmentation, the Product Pricing and the Product Cost.
The UIF framework differentiates in a fundamental way between innovation and invention. Within this framework, an invention or a patent is always attached to the product only, and is one, but not necessarily the only or even strongest source of a Sustainable Competitive Advantage (SCA). On the other hand, other sources of SCA may be identified alternatively or in addition to a patent, such as a defensible business model, or a customer lock-in, that offer a strong and sustainable competitive advantage.

Figure 3: Universal Innovation Framework

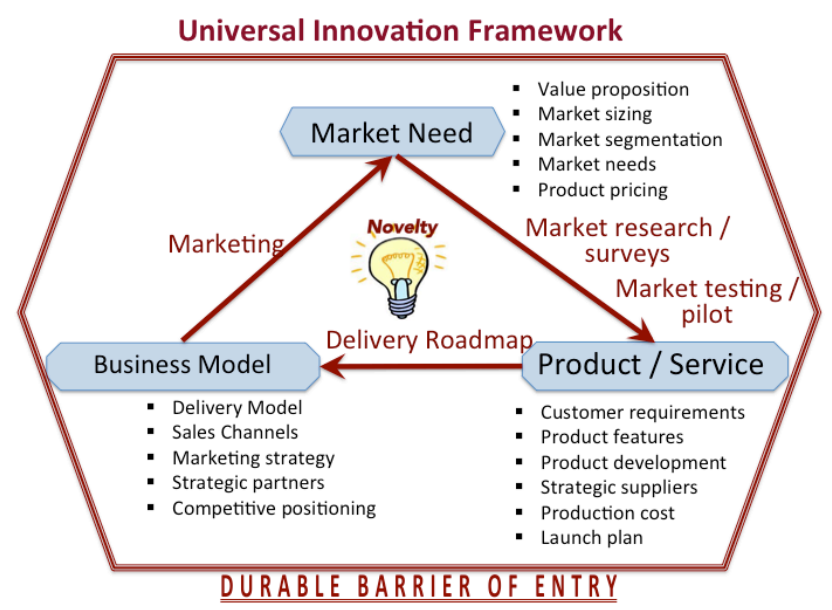

\section{PROGRAM DESIGN}

Our Entrepreneurship program consists of a "Stage \& Gate" model that essentially leads the student to the (i) discovery, (ii) the development and finally (iii) the deployment of their new enterprise according to the roadmap provided by the UIF.

\subsection{Stage \& Gate Model}

Figure 4 illustrates our Entrepreneurship Program, which amounts essentially to a stage-gate adaptation of the LSM, and where our UIF provides a roadmap for the integration of the customer development, the product development process, as well as the business model development. Besides providing a generally applicable framework, this model lends itself to a methodical experiential curriculum that is coherent, structured and disciplined. 
Figure 4: Enterpise Development Model - A stage-gate adaptation of the Lean Startup Model with the UIF as a roadmap

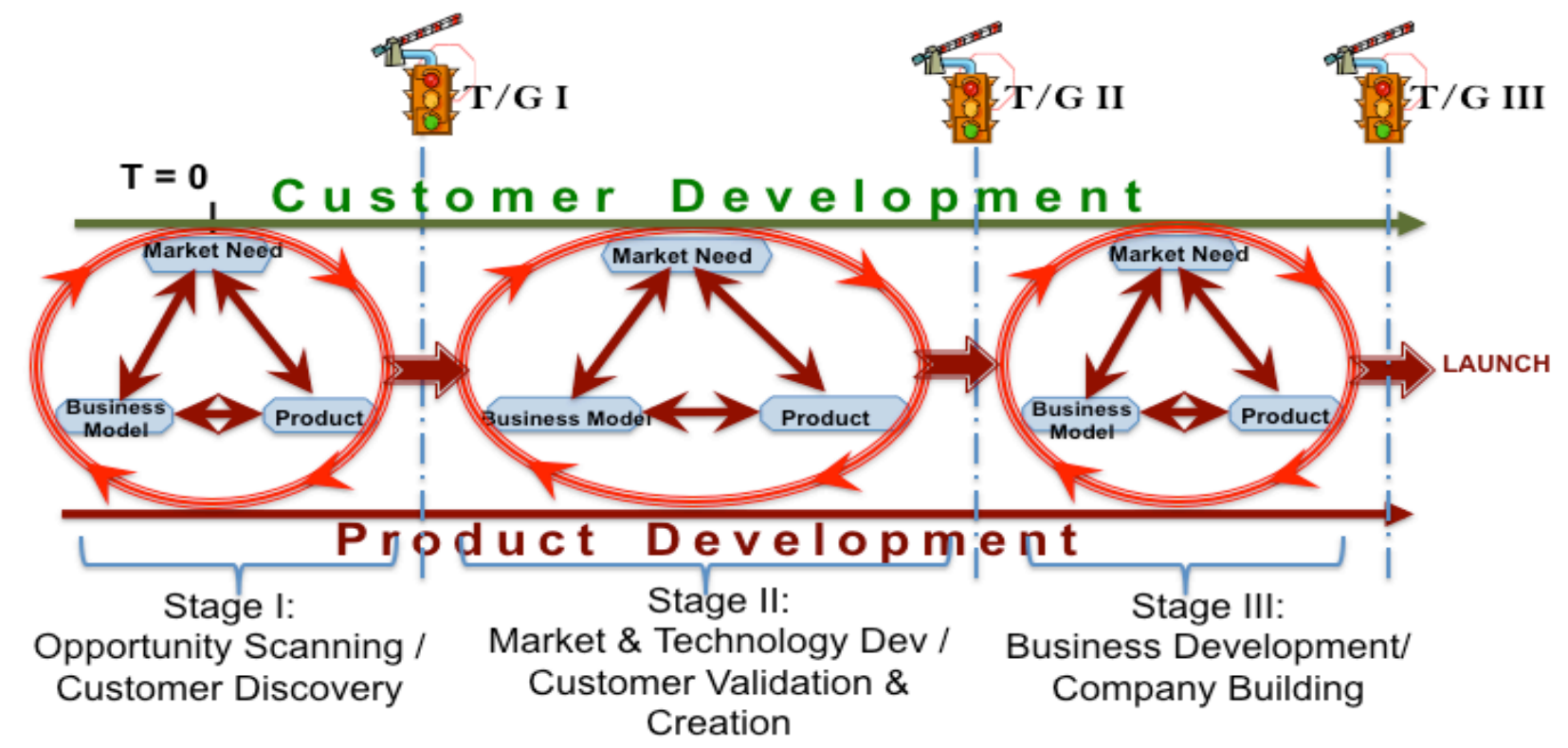

Figure 5: Stage I of the Enterprise Development process per the UIF Roadmap

\subsection{Stage I: Opportunity Scanning/Customer Discovery}

Stage I is called the "Opportunity Scanning" stage and is the equivalent of the "Customer Discovery" phase in the LSM. During that phase, the student takes a core course where he/she learns the basic "Entrepreneurial Skills and Processes", and is led through the selection of a project and a team. In order to stimulate and facilitate the project and team selection, the class is first exposed to several student-led as well as external speakers short presentations of potential enterprise projects. Following the presentations, the students must attend a four-hour team forming session that is a combination of a brainstorming and a poster session. The objective of this session is to encourage the students to become familiar with all the potential projects that are looking for additional team members as well as identify additional members for their own project if they happen to have their own idea. The students are also encouraged to critique each other ideas and evaluate the potential projects using the UIF as a selection lens. Following this session, the students must submit an individual assignment within 3 weeks that describes their team and project and the rational behind their selection. The rest of the course leads the students through the appropriate learning and assignments that lead the student to articulate the key components and attributes of the UIF for their Enterprise project, as well as the first level elements of the UIF as described by Figure 5 below.
STAGE 1: OPPORTUNITY SCANNING

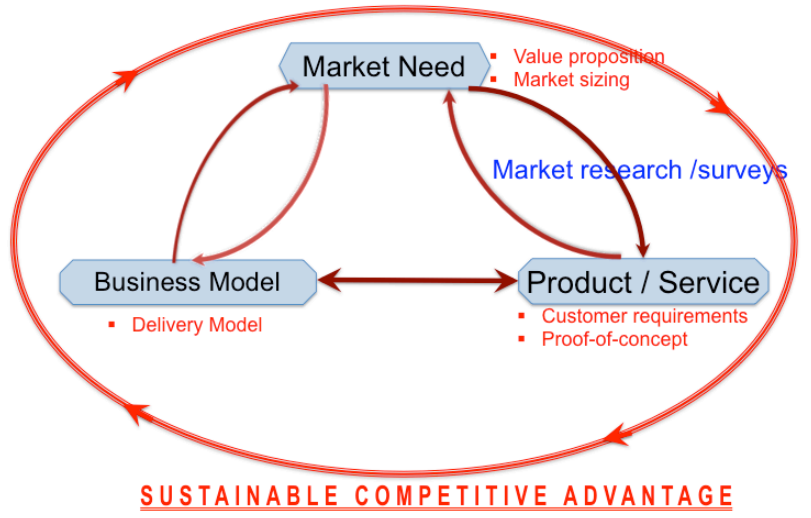

\subsection{Stage II: Market \& Technology Development / Customer Validation \& Creation}

Stage II combines two phases of the LSM, namely the Customer Validation and Customer Creation into a single one, and represents the longest as well as the most critical stage of the program. During this stage, the student learning is supported by two separate core modules; i.e. "Breakthrough Technology Development" and "Shaping \& Positioning the Enterprise". The two courses equip the student with all the tools and learning they need to concurrently develop both their market and their product, taking into account their business model. The assignments of both courses are designed to lead the students to develop the essential elements of their Enterprise project according to the UIF roadmap as shown in Figure 6. 
Figure 6: Illustration of Stage II of the UIF Roadmap.

\section{STAGE 2: TECHNOLOGY \& MARKET DEVELOPMENT}

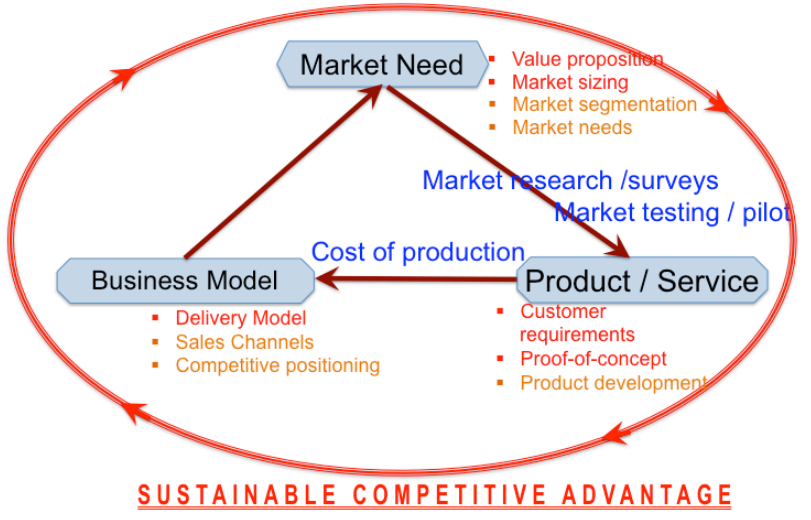

At the conclusion of Stage II, many teams would have pivoted at least once from their initial project. Some teams would have disbanded and reformed, or others would have either lost or gained an extra member. During Stage II, the students would have learned the House Quality tool on how to map market requirements into product features and applied it to their own project. They would also have learned how to make position their product more competitively by making their technology more disruptive, or shifted to a different market audience or a more disruptive business model. They also are led through key assignments to collect market information directly from their potential customers and end-users, learn the basics of managerial accounting and corporate finance, develop a clear understanding of the various kinds of financing capital and its associated cost, investment instruments and term-sheet negotiation skills with investors. Some of the key deliverables of this stage are (i) intellectual property protection strategy, (ii) a topdown and bottom-up market research, (iii) a marketvalidated proof of concept and (iv) a 5-year financial plan based on validated market, product and business-model assumptions.

\subsection{Stage III: Business Development / Company Building}

In this final stage, the student team starts developing the Business Strategy and the Marketing Plan for their company, again using the UIF as a roadmap, as shown in Figure 7. The student's learning is supported by the last two core modules of our program, namely "New Venture Business Strategy" and "Taking the New Venture to Market". Some of the key tools the student learns are the use of the Decision Matrix to select their best business strategy, writing and negotiation of sales and suppliers contracts, development of a marketing and launch plan, setting up of a supply chain and hiring and management of additional key resources.

This represents the final stage by which the student team is finally ready to complete and present their final deliverable of the program, i.e. full Business Plan. Note that unlike the traditional model of teaching entrepreneurship where writing a Business Plan based on untested assumptions comes first, in our program, the Business Plan is the very last deliverable which represents the convergence of the market need, the product and the business model through a holistic and structured innovation model of new enterprise development.

Figure 7: Final Stage III of the Enterprise Development process as illustrated by the UIF Roadmap.

\section{STAGE 3: BUSINESS DEVELOPMENT}

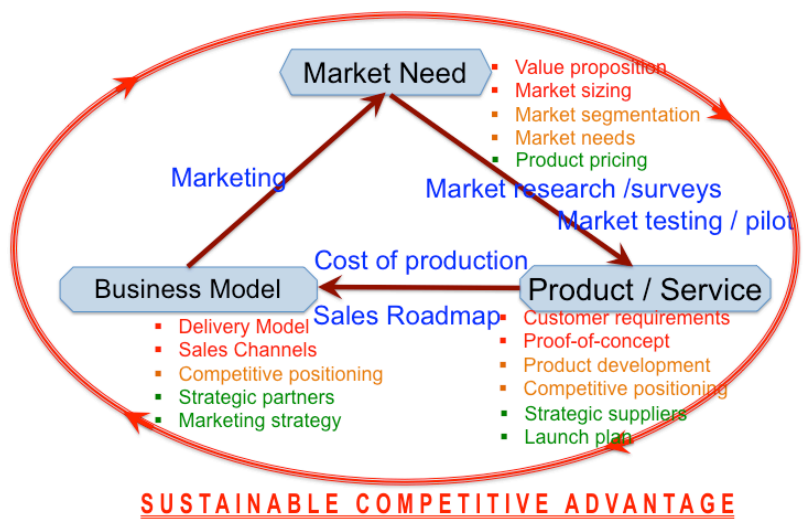

\subsection{The Program at a Glance}

In Figure 8, we show an illustration of our full program as represented by its three stages, its five core modules and its typical timeline. Note that the completion of each stage by a student must go through a "tollgate" presentation by the student team to an Advisory Committee composed of the team's faculty advisor, a technical and a business mentor and a business development manager. The successful completion of the Tollgate III and the approval of the Business Plan by the student's Advisory Committee clears the student for graduation in their Master's degree for Engineering, Entrepreneurship \& Innovation (MEEI). 

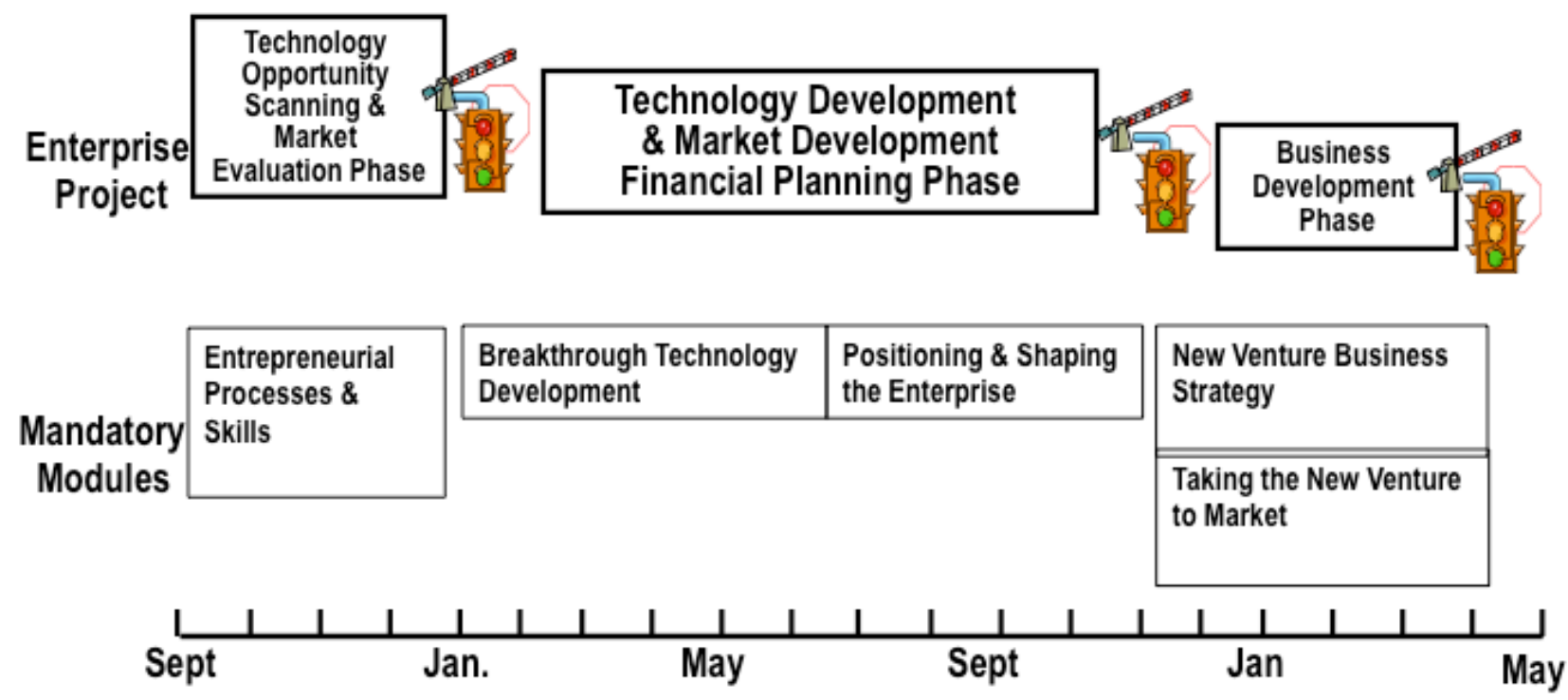

\section{CONCLUSIONS}

Our contribution in this paper is two fold:

(i) We have introduced a novel Universal Innovation Framework (UIF) that offers a general and practical roadmap for the discovery, development and deployment of technology-based new enterprises, and enables a structured and methodical teaching of innovation-based entrepreneurship. It also offers a very distinctive and holistic anatomy of innovation that exemplifies its social character in contrast with the concept of invention that is inherently technical in nature.

(ii) We have presented how the UIF is currently being used at the Xerox Centre for Engineering, Entrepreneurship \& Innovation (XCEEI) at McMaster University in the design and delivery of our experiential Entrepreneurship program, and the effective coaching of tomorrow's entrepreneurs.

\section{Acknowledgements}

I am deeply indebted to Dr. Rafik Loutfy, the inaugural director of the Xerox Centre for Engineering, Entrepreneurship \& Innovation (XCEEI) for his guidance, insight and mentorship throughout the years, and without which the development of this entrepreneurship program or the innovation would not have occurred. (Cat07)

Also, I would like to acknowledge the support of the Xerox Centre of Engineering, Entrepreneurship and Innovation (XCEEi), the W Booth School of Engineering Practice, as well as the Dean of the Faculty of Engineering for their generous and multi-faceted support without which this program would not have been possible.

\section{REFERENCES}

[1] Kauffman Foundation, "Entrepreneurship Education Comes of Age in Campus: The Challenges and rewards of bringing entrepreneurship to higher education", August 2013 (see

http://www.kauffman.org/newsroom/2013/08/entrepreneur ship-education-comes-of-age-on-campus)

[2] Tim Kane, the Kauffman Foundation, July 2010 (see http://www.kauffman.org/ /media/kauffman_org/research $\% 20$ reports\%20and\%20covers/2010/07/firm_formation_i mportance_of_startups.pdf)

[3] Eric Ries, "The Lean Startup: How Today's Entrepreneurs Use Continuous Innovation to Create Radically Successful Businesses", Random House 2011.

[4] Steve Blank, "The Four Steps to the Epiphany", 2nd Edition, 2013

[5] Steve Blank, "Why the Lean Start-Up Changes Everything", Harvard Business Review, May 2013.

[6] Nobel, Carmen, and Shikhar Ghosh. "Why Companies Fail--and How Their Founders Can Bounce Back." HBS Working Knowledge, March 7 (2011).

[6] Edward B. Roberts, What we have learned: Managing Invention and Innovation, Research Technology Management, 1. P 11-29 (1988)

[7] H. E. Potts, "The Definition of Invention in Patent Law", v.7 p 113-123 (July, 1994) 